\title{
E1 Reino Wiman Joseon: aproximaciones y perspectivas en torno a sus antecedentes y caracteres
}

\author{
[The Wiman Joseon Kingdom: Approaches and Perspectives on its \\ Antecedents and Features] \\ Gustavo E. Santillán \\ (CONICET-Universidad Nacional de Córdoba) \\ gustavo.santillan@conicet.gov.ar \\ José María Resiale Viano \\ (CONICET-Universidad Nacional de Córdoba) \\ jresiale@hotmail.com.ar
}

\begin{abstract}
Resumen
Las Memorias Históricas de Sima Qian describen la asunción al trono de Joseon por parte de Wiman en 194 a.C., en el norte de la península coreana. A partir de allí, Joseon continuó su existencia como reino hasta su caída a manos de tropas Han, en 108 a.C. Sin embargo, Sima Qian no da demasiados detalles acerca de la entidad del Estado. Además, la historiografía coreana moderna establecía tradicionalmente la preexistencia de Joseon hasta el siglo XXIV a.C., desde la fundación del Estado por Dangun. Finalmente, trabajos más recientes ponen en cuestión la existencia histórica misma de Joseon como Estado. Este artículo sistematiza estas perspectivas revisando: a) las Memorias Históricas y la literatura sinológica, y b) La literatura académica especializada sobre Corea. El trabajo supone por ende un primer ordenamiento de estas perspectivas en nuestro medio, aportando a la comprensión de los orígenes del Estado en la península coreana.
\end{abstract}

Palabras clave: Joseon - Sima Qian -Historiografía Estado

\begin{abstract}
The Historical Memoirs by Sima Qian depict the enthronement of Wiman in Joseon, occurred in 194 B.C. in the Northern part of the Korean Peninsula. Since then, Joseon continued its existence as a kingdom until its fall in the hands of Han troops in 108 B.C. However, Sima Qian does not provide too many details of the State entity. Besides, the modern Korean historiography traditionally established the preexistence of the Joseon Kingdom back to the 24th Century B.C., since the foundation of the State by Dangun. Finally, more recent scholarship raises questions even on the very historical existence of Joseon as a State. This article systematizes these perspectives by reviewing: a) The Historical Memoirs and the Sinological literature, and b) the specialized academic literature on Korea. The paper implies therefore a first ordering of these perspectives within our milieu, helping to understand the origins of the State in the Korean Peninsula.
\end{abstract}

Keywords: Joseon - Sima Qian - Historiography State

Recibido: 01/06/2017

Evaluación: 08/08/2017

Aceptado: 28/11/2017

Anuario de la Escuela de Historia Virtual - Año 9 - No 13 - 2018: pp. 1-23.

ISSN: 1853-7049

http://revistas.unc.edu.ar/index.php/anuariohistoria 


\section{E1 Reino Wiman Joseon: aproximaciones y perspectivas en torno a sus antecedentes y caracteres}

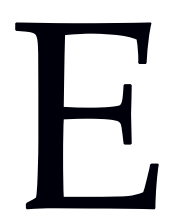

ste trabajo pretende introducir en nuestro medio un problema de alta relevancia para la comprensión de los orígenes del Estado en la península coreana, a saber: la conformación del Reino Wiman Joseon ${ }^{1}$ (ch. Weiman Chaoxian), sus antecedentes y caracteres. Se propone abordar el problema mencionado, primero, a través de la exposición de su tratamiento en las fuentes chinas y la literatura sinológica especializada, con énfasis en la exposición de la creación de Weiman Chaoxian y de sus antecedentes en las Memorias Históricas (Shiji, 史記 - simpl. 史记) de Sima Qian (¿145-86 a.C.?), completadas por el autor entre el 104 y el 99 a.C. y a partir de la obra de su padre, Sima Dan (m. 110 a.C.). Se expone seguidamente el tratamiento del mismo problema en el campo de los Estudios Coreanos, que discuten la conformación de Joseon ${ }^{2}$ desde una perspectiva distinta, condicionada primero por el establecimiento de una linealidad que ubica a Joseon como sucesor de un reino primigenio, fundado por Dangun en el siglo XXIV a.C. Luego, trabajos más recientes revirtieron drásticamente estas perspectivas, impugnando la existencia misma del Estado hasta la invasión del Reino de Joseon por parte de las tropas chinas de la Dinastía Han Anterior, en 108 a.C. Del desarrollo de estas dos secciones, extraemos finalmente nuestras conclusiones.

Es preciso aclarar que este contraste de perspectivas supone la adopción implícita de una concepción acerca del Estado y de sus orígenes. Para clarificar de manera mínima esta cuestión en los límites del presente trabajo, sólo diremos (no pretendiendo formular ni discutir teorías acerca del origen y desarrollo del Estado), que existen algunas características comunes a todas las organizaciones socio-políticas que han sido generalmente definidas como Estados. En este sentido, podríamos decir que estamos en presencia de un Estado cuando pueden identificarse:

a- Una sociedad estratificada, dentro de la cual el grupo social privilegiado ha logrado hacerse con el dominio de;

b- Un gobierno centralizado, el cual se mantiene en el poder gracias al control de;

c- Una fuerza pública que mantiene el monopolio de la coacción física.

d- Un territorio delimitado, el cual es administrado a través de;

\footnotetext{
${ }^{1}$ De acuerdo con Sima Qian, y como detallamos a continuación, en 194 a.C.

2 En esta introducción hablamos de Chaoxian cuando referimos al Shiji, y a Joseon cuando aludimos a la terminología de los estudios coreanos. Evidentemente, ambos términos designan a la misma entidad. Aclararemos a continuación las denominaciones que usaremos en las dos secciones del presente artículo.
} 
e- Un grupo dirigente o burocracia. ${ }^{3}$

En el desarrollo del texto, veremos cómo algunos de estos elementos constitutivos del Estado aparecen en referencia a Joseon/Chaoxian, ya en las fuentes históricas, o bien afirmadas y/o impugnadas por la literatura específica. Podremos concluir, todo lo más y a partir de esa revisión, que pueden advertirse algunos indicios de estatalidad en la frontera nororiental del mundo chino, para el periodo abierto con la emergencia de Wiman Joseon.

El artículo posee en nuestro medio el valor del contraste señalado entre la historiografía china clásica y la sinología (que se sirve con mayor frecuencia de estas fuentes escritas) por un lado, y el campo de los Estudios Coreanos por el otro. En segundo lugar, resulta valiosa la exposición y traducción en español de extractos relevantes del Shiji. Para acometer esta tarea, hemos utilizado fundamentalmente la edición traducida al inglés por el equipo de William Nienhauser (Nienhauser, 1994; 2006; 2008; 2016). Sin embargo, allí donde surgieron dudas o nociones relevantes que creímos necesario especificar, hemos procurado su cotejo con el original chino, y con traducciones alternativas (por otra parte incompletas) como la de Burton Watson, y como el ya clásico trabajo de Édouard Chavannes. ${ }^{4}$ Un trabajo análogo de análisis de fuentes primarias y li-

${ }^{3}$ En una de sus obras clásicas, Engels (2017, pp. 149-157) señalaba, en relación al surgimiento del Estado en Atenas, que “los (...) grupos constituidos por la división del trabajo (...) habían creado nuevos órganos para la defensa de sus intereses", y que a partir de allí el joven Estado tuvo la necesidad de una fuerza propia; en este sentido, agregaba: "Uno de los caracteres esenciales del Estado es la existencia de una fuerza pública aparte de la masa del pueblo". En la misma línea, Lenin afirmaba en 1919 que el Estado era "el aparato esencial para el empleo sistemático de la fuerza y el sometimiento del pueblo por la fuerza". El Estado solamente surge "cuando aparece la división de la sociedad en clases, o sea, la división de grupos de personas, algunas de las cuales se apropian permanentemente del trabajo ajeno...". En este sentido, el grupo de personas que se apropian del trabajo ajeno conforma, además, un grupo dedicado "exclusivamente a gobernar y que para gobernar necesitan de una aparato especial de coerción para someter la voluntad de otros por la fuerza." (Lenin, 1987, pp. 318-319). Por otra parte, Max Weber (2002, p. 1057) consideraba que el Estado "lo mismo que las demás asociaciones políticas que lo han precedido es una relación de dominio de hombres sobre hombres apoyado en el medio de la coacción legítima (...) para que subsista (el Estado) es necesario que los hombres dominados se sometan a la autoridad de los que dominan". Estudios más actuales (Cohen, 1978) sostienen que la dominación de un grupo sobre otro a través del uso del Estado es una característica universal de las primeras formaciones políticas; no obstante, a diferencia de los teóricos marxistas, no se considera aquí a la división de clases o a la especialización de los diferentes grupos sociales como una causa del nacimiento de los Estados, sino, más bien, como una característica de los mismos. Ya algunos antropólogos clásicos, como S. Nadel, E.E. Evans-Pritchard y M. Fortes, identificaron inclusive como características propias de las formaciones estatales a la presencia de un gobierno centralizado, de una soberanía territorial y de un grupo dirigente. Estas características fueron compartidas por E. R. Service, quién además incorporó el monopolio de la fuerza como rasgo. A esto, Cohen también añade la importancia de la tarea desempeñada por la burocracia, entendida como "un conjunto de funcionarios, sacerdotes, nobles, esclavos (...) y sus suborganizaciones que administran la maquinaria administrativa de la jerarquía estatal que tiene la tarea principal de mantener la continuidad del Estado". (Cohen, 1978, pp. 33-35).

${ }^{4}$ El original chino, tomado de las Veinticuatro Historias Estándar, consta en Sturgeon (2017a). cf. Swingle (1921, pp. 717-725). Del mismo modo se ha procedido para las menciones al Shangshu (original en Sturgeon, 2017c). En este caso, la edición facsimilar es una reproducción de los Trece Clásicos editados por Wang Yinglin durante la Dinastía Song del Sur (1127-1279). cf. Rakita Golding (2001, pp. 86-97). Las traducciones 
4 | El Reino Wiman Joseon: aproximaciones y perspectivas...

teratura ha sido realizado por especialistas en Estudios Coreanos, de manera que en la segunda sección la revisión será fundamentalmente bibliográfica. Esta aproximación se justifica además en función del carácter seminal de las fuentes chinas para la narración del periodo: como iremos a estipular, buena parte de las fuentes coreanas sobre Joseon tiene su referencia en las fuentes históricas chinas. Cabe reiterar al respecto, que no contamos con estudios directos similares que enfoquen nuestro objeto de estudio en lengua castellana y con base en fuentes chinas y en la literatura sinológica.

Dado que tanto la entidad política analizada como su soberano poseen dos denominaciones y romanizaciones distintas, en chino y en coreano, y que el propósito de nuestro trabajo es el cotejo de las visiones existentes en las fuentes chinas y la sinología por un lado, y los estudios coreanos por el otro, mantuvimos la designación respectiva en cada apartado. En el título del trabajo, en tanto, se sostiene la romanización coreana.

Para la romanización de nombres chinos, se han transcripto en pinyin las citas textuales de fuentes para mayor exactitud en la identificación de nombres propios y toponímicos, aun cuando el original utilice otro sistema de romanización. Para las citas bibliográficas, en cambio, se ha realizado una transcripción literal, indicándose a pie de página la romanización utilizada por los autores. Para los nombres coreanos, utilizamos la romanización revisada.

\section{Chaoxian en las fuentes chinas}

En las Memorias Históricas de Sima Qian ${ }^{5}$ la primera mención a Chaoxian ocurre al relatar acontecimientos que anteceden en más de ochocientos años al periodo que nos ocupa, la emergencia, consolidación y exterminación del Reino Weiman Chaoxian. Sima Qian nos cuenta cómo a comienzos de la Dinastía Zhou su fundador y primer soberano, el Rey Wu (r. 1045-1043 a.C.), otorgó un feudo territorial, Chaoxian, a un príncipe sobreviviente de la recientemente derrotada Dinastía Shang (s. XVI a.C.-1045 a.C.), Jizi (箕子). ${ }^{6}$ El relato es el siguiente: ${ }^{7}$

El Vizconde de $\mathrm{Ji}^{8}$ era un pariente de Zhou ${ }^{9}$. Cuando Zhou empezó a hacer palillos de

alternativas mencionadas, en Watson (1993) y Chavannes (1967, 6 vols.). Esta última traducción se detiene en el capítulo 52 del Shiji, a diferencia de la colección (también parcial) de Watson, que incluye fragmentos posteriores.

${ }^{5}$ Acerca de las fuentes en las que Sima Qian a su vez abreva, daremos más detalles a lo largo de esta sección. Con posterioridad a la obra de Sima Qian, pasajes paralelos referentes a Chaoxian aparecen en la Historia de la Dinastía Han (Hanshu) y la Historia de los Han Posteriores (Houhanshu). Daremos referencias ocasionales a estas obras en los casos en los que lo consideremos relevante. Aún con posterioridad, la Crónica de los Tres Reinos (Sanguozhi) replica la historia. Las primeras fuentes coreanas que mencionan a Joseon abrevan fundamentalmente en Sima Qian. cf. infra, p. 12.

${ }^{6}$ Cor. Gija

7 Shiji, 38 (Nienhauser, 2006, pp. 267-297).

${ }^{8}$ Dado que exponemos con literalidad la traducción de Nienhauser, transcribimos Jizi (箕子) por "El Vizconde de Ji" (título que es hasta cierto punto aceptado en la sinología para los rangos Zhou), como traduce 


\section{5 | Gustavo E. Santillán y José María Resiale Viano}

marfil, el Vizconde de Ji suspiró, diciendo: '(Dado que) hace palillos de marfil, seguramente hará vasos (de jade); (dado que) hace vasos (de jade), seguramente anhelará las cosas preciosas y raras de tierras lejanas, y las usará. La creciente (extravagancia en) carruajes y caballos, palacios y salones, empezará por esto, y Jizi ya nunca podrá ser rescatado. ${ }^{10}$. Cuando Zhou se dio al libertinaje, el Vizconde de Ji intentó advertirlo, pero Zhou no habría de escucharlo. Alguien dijo, 'Puedes irte a causa de esto'. El Vizconde de Ji replicó, 'Como vasallo, si me voy sólo porque he intentado advertir a mi señor y él no me ha escuchado, esto sería mostrar las malas acciones de mi señor e intentar congraciarme con el pueblo. No soporto hacer esto.' Entonces, soltando su cabello, simuló estar loco y se convirtió en un esclavo. Más tarde vivió como ermitaño, y en ocasiones tocaba una cítara para darse lástima. ${ }^{11}$ Por estas razones, (la música que tocaba) se llamó 'El Lamento del Vizconde de Ji'..12

(...)

Luego de que el Rey Wu derrotara a los Yin ${ }^{13}$, visitó al Vizconde de Ji.

El Rey Wu dijo, '¡Ah! Sólo es el Cielo el que estabiliza de manera silenciosa al pueblo allí abajo, ayudándolos a vivir juntos en armonía (sic). ${ }^{14}$ (Pero) yo no conozco el orden de las guías constantes (que usa el Cielo para estabilizar al pueblo)'.

El Vizconde de Ji respondió, 'En el pasado, Gun intentó bloquear la inundación, y tiró a los Cinco Elementos en desorden. El Soberano de Arriba estalló entonces en ira, dado que Gun no siguió las nueve categorías de los Grandes Modelos. ${ }^{15}$ Las guías constantes fue-

el editor. En el original inglés, "The Viscount of Chi” (Wade Giles en Nienhauser). Sólo hemos reemplazado esta romanización por la más actual pinyin. Cabe enfatizar, por ende, que Jizi y el Vizconde de Ji son la misma persona. La traducción de Legge que utilizamos con posterioridad para las Analectas, también denomina "Vizconde de Ji" a Jizi. Por otra parte, es asimismo evidente que el coreano Gija también designa a Jizi, como se acaba de señalar en n.6.

${ }^{9}$ Zhouxin, el último monarca Shang (r. 1085-1045 a.C.). De acuerdo a Nienhauser, Jizi era tío o hermano mayor de Zhouxin (Nienhauser, 2006, p. 269, n. 28).

10 "A partir de este momento, él comenzará (a desear) un número cada vez mayor de equipamiento y de caballos, y no habrá manera de rescatarlo" (Chavannes, 1967, vol. IV p. 217). En el original chino, sistematizado y digitalizado por Sturgeon, se lee: 輿馬宮室之漸自此始，不可振也. Shiji, 38, 2 (Sturgeon, 2017b). El pasaje corresponde al facsímil principal utilizado en Sturgeon (2017a, p. 107).

11 "tocaba una cítara para expresar su tristeza" (Chavannes, 1967, vol. IV, p. 217). En el original chino sistematizado y digitalizado por Sturgeon se lee: 鼓琴以自悲. Shiji, 38, 2 (Sturgeon, 2017b). El pasaje corresponde al facsímil principal utilizado por Sturgeon (2017a, p. 108).

12 Nienhauser, 2006, p. 269.

13 i.e., la Dinastía Shang .

14 "Ah! El Cielo, por su acción secreta, determina (la vida) del pueblo ahí abajo, y lo ayuda a vivir en armonía..." (Chavannes, 1967, vol. IV, p. 218). La expresión en inglés de Nienhauser es, en cambio: "Alas! It is only Heaven that silently stabilizes the people below, helps them live together in harmony." (subrayado nuestro). En el original chino sistematizado y digitalizado por Sturgeon se lee: 於乎 ! 維天陰定下民, 相和 其居. Shiji, 38, 8 (Sturgeon, 2017b). El pasaje corresponde al facsímil principal utilizado por Sturgeon (2017a, p. 109). La diferencia se explica por el caracter 相, que significa "mutuo" o "en conjunto". Al traducir al castellano el sustantivo colectivo "people" por "pueblo", el resto de la redacción debe pluralizarse. A pesar de este inconveniente, encontramos más apropiado mantener la traducción de Nienhauser por su mayor fidelidad al original.

${ }^{15}$ Chavannes: “El Emperador (celeste) estalló entonces en cólera; él ya no le comunicó las nueve secciones del Gran Plan”. En el original chino sistematizado y digitalizado por Sturgeon se lee: 帝乃震怒, 不從鴻範 九等. Shiji, 38, 9 (Sturgeon, 2017b). El pasaje corresponde al facsímil principal utilizado por Sturgeon (2017a, p. 109). En este caso, a diferencia de la traducción realizada por Nienhauser, la expresión aceptada es "Plan"(fan, 範), ya que remite al capítulo Hongfan del Shangshu (cf. infra, pp. 6-7) y no "modelos" (como también puede leerse 範). Al contrario, 帝 (di) parece indicar el Soberano de Arriba (shangdi, 上帝) reverenciado inicialmente por la Dinastía Shang. 
6 | El Reino Wiman Joseon: aproximaciones y perspectivas...

ron socavadas.

Gun fue entonces hecho muerto, y Yu tomó su sucesión y ascendió. El Cielo, entonces, le otorgó a él las nueve categorías de los Grandes Modelos. ${ }^{16}$ Y las guías constantes estuvieron en orden. ${ }^{17}$

Jizi dio entonces a $\mathrm{Wu}$ un largo exordio sobre estas categorías (la primera son los Cinco Elementos - agua, fuego, madera, metal y tierra -; la segunda son las Cinco Conductas - apariencia, discurso, observación, escucha y pensamiento -; la tercera son los Ocho Asuntos de Gobierno - comida, bienes y mercancías, sacrificios, educación, seguridad, huéspedes y tropas -; la cuarta son los Cinco Reguladores - años, meses, días, estrellas, cálculos del calendario -; la quinta es la Perfección Augusta; la sexta son las Tres Disposiciones - Justicia y Rectitud, Superación de la Firmeza y Superación de la Suavidad -; la séptima es el Examen de las Dudas; la octava son las Verificaciones Diversas - lluvia, sol, calor, frío, viento y oportunidad -; y la novena es el Disfrute de las Cinco Fortunas y el Miedo a los Seis Extremos. Respectivamente, las Cinco Fortunas son la longevidad, la riqueza, la salud y la paz, la cultivación de la buena virtud, y el envejecer y morir de muerte natural; los Seis Extremos son la muerte prematura, la enfermedad, la ansiedad, la pobreza, la fealdad y la debilidad. ${ }^{18}$

Tras recibir estas reflexiones por parte de Jizi, "el Rey Wu enfeudó al Vizconde de Ji con Chaoxian, pero él (el Vizconde de Ji) no se consideró a sí mismo como un vasallo de Zhou". ${ }^{19}$

Aquí debemos dudar de la exactitud de Sima Qian, por cuanto la crónica que acabamos de citar pone en boca de sus protagonistas un lenguaje ya casi plenamente confuciano, que no coincide exactamente con la cosmovisión del siglo XI a.C. Ello es evidente en el pasaje antecitado, cuando Jizi replica a un interlocutor que "Como vasallo, si me voy sólo porque he intentado advertir a mi señor y él no me ha escuchado, esto sería mostrar las malas acciones de mi señor e intentar congraciarme con el pueblo. No soporto hacer esto". Esta argumentación tiene una evidente correlación con la posición sentada por Confucio en las Analectas, donde se plantea reiteradamente la responsabilidad de los funcionarios y los dilemas de ella derivados. Más aún, en las Analectas se glosa ya el infortunio de Jizi: “El Vizconde de Wei se retiró de la corte. El Vizconde de Ji se convirtió en un esclavo de Zhou (Xin). Bi Gan amonestó (a Zhouxin) junto a él, y

\footnotetext{
${ }^{16}$ cf. n. 15

${ }_{17}$ Nienhauser (2006, p. 271).

18 Nienhauser (2006, pp. 271-276).

${ }^{19}$ Nienhauser glosa un pasaje antecedente relevante: “Takigawa (38.21) señala que 'el Shangshu Dazhuan (尚書大傳) dice que el Rey Wu (de Zhou) derrotó a Yin y liberó al Vizconde de Ji. Pero el Vizconde de Ji no pudo soportar ser liberado por Zhou, de manera que se fue a Chaoxian. Habiendo escuchado esto, el Rey Wu le confirió Chaoxian como feudo. Luego de recibir la oferta de Zhou, el Vizconde de Ji tuvo que mostrar cortesía como vasallo. Así que vino a ofrecer sacrificio (a los ancestros de Zhou) en el decimotercer año. Esto difiere de la narración hecha aquí."” (Nienhauser, 2006, p. 276, n.96). El Shangshu Dazhuan es una versión amplificada y comentada del Shangshu en escritura "moderna" (jinwen, 今文), transcripta posiblemente por Fu Sheng (¿264-170 a.C.?) durante la Dinastía Qin (221-206 a.C.) (Yao, 2003, pp. 217-218).
} 
murió. Confucio dijo, 'la Dinastía Yin tuvo a estos tres hombres virtuosos'”. ${ }^{20}$ En segundo lugar, Sima Qian hace hablar a Jizi en términos de la Doctrina de los Cinco Elementos. El exordio de Jizi en el que ello ocurre aparece también en el capítulo Hongfan del Libro de los Documentos (Shangshu), cuya redacción ha sido estimada por la sinología occidental en torno al siglo V a.C. (Harper, 1999, p. 863; Nylan, 2001, pp. 139-142) Con posterioridad, la Doctrina de las Cinco Fases fue asociada a las nociones del yin y el yang alrededor de los siglos IV y III a.C. (Nivison, 1999, p. 810) y puesta en boga en la corte y los ambientes letrados durante la Dinastía Han Anterior (206 a.C.-9 d.C.), fundamentalmente bajo la influencia de Dong Zhongshu (¿197-104 a.C.?), contemporáneo de Sima Qian. ${ }^{21}$ Con mayor precisión, debemos señalar que la fuente de Sima Qian ha sido, aparentemente, la versión en textos modernos del Shangshu, comentada por Fu Sheng (Shangshu Dazhuan, 尚書大傳, lit. “Gran Comentario a los Documentos Venerados" -cf. supra, n. 19). Esto es importante, porque los textos modernos (jinwen, 今文) fueron las versiones preferidas por los Han Anteriores para su canonización como Clásicos; esta elección fue hecha a instancias de los eruditos de la época y por motivos políticos, a fin de garantizar una legitimidad apropiada tanto a su propio estrato como a la floreciente nueva Dinastía, vis-á-vis el acerbo anticonfucianismo de la Dinastía Qin (Cheng, 2002, pp. 261-269). Entre estos letrados, por supuesto, descollaban Dong y Sima. Este panorama cambió entre los dos periodos dinásticos Han (9-23 d.C.), tras el supuesto descubrimiento de versiones de los Clásicos en "textos antiguos" (guwen, 古 文). De allí en más, y con la notable excepción de la reflexión confuciana durante el siglo XIX, las versiones en textos antiguos son las que constan como canónicas. ${ }^{22}$

En lo referente a Chaoxian, una ambigüedad interesante reside en el señalamiento de su existencia como reino "no vasallo" tras su inicial atribución por Wu. Esta discordancia también se desprende del cotejo de Sima Qian con su fuente (cf. supra, n. 19), y

\footnotetext{
${ }^{20}$ Analectas, XVIII, “Weizi”, 1 (Legge, 1861, p. 195). Además, son relevantes los siguientes pasajes: “El Maestro dijo, 'Con confianza sincera él se une al amor del aprendizaje; aferrándose a la muerte, él se perfecciona en la excelencia de su Vía. Tal hombre no irá a entrar en un Estado tambaleante, ni habita en un Estado desorganizado. Cuando los principios adecuados de gobierno prevalecen en el reino, él se mostrará; cuando estos principios están trastornados, él permanecerá oculto. Cuando un país está bien gobernado, la pobreza y la condición precaria son cosas de las que avergonzarse. Cuando un país está mal gobernado, las riquezas y el honor son cosas de las cuales avergonzarse." (Analectas, VIII, “Tai Bo", 13, en Legge, 1861, p. 76); “Zi Gong preguntó, diciendo: '¿Qué dices de un hombre que es amado por todo el pueblo de su aldea?' El Maestro respondió, 'podemos o no acordar con la aprobación hacia él'. '¿Y qué dices de el que es odiado por todo el pueblo de su aldea?' El Maestro dijo, 'no podemos concluir que es malo. Es mejor que en cada uno de estos casos, los buenos de la aldea lo amen, y los malos lo odien."' (Analectas, XIII, "Zi Lu", 24, en Legge, 1861, p. 137).

${ }^{21}$ El Shiji contiene una semblanza biográfica de Dong Zhongshu. Aunque escueta, está escrita en términos elogiosos. En ella se destaca el énfasis reiterado por Dong en la teoría de las Cinco Fases, asociada al flujo del yin y el yang. cf. Loewe (2011, pp. 43-47).

22 El Shangshu Dazhuan, amén de su escritura original de memoria por parte de Fu Sheng a partir de su recuerdo del original del Shangshu destruido por Qin Shihuangdi, sufrió diversas reediciones, permaneciendo fragmentario. Vale para nuestros propósitos, sin embargo, su utilización por parte de Sima Qian en las Memorias Históricas y, por supuesto, su evidente relación con el ambiente neoconfuciano de los Han Anteriores.
} 
8 | El Reino Wiman Joseon: aproximaciones y perspectivas...

nos permite inferir el carácter indeterminado de la relación entre Chaoxian y el Estado Zhou a partir del siglo XI a.C. ¿Fue Chaoxian un reino "vasallo" de Zhou, una enfeudación que escapó posteriormente a su control (como indica Sima Qian), o una concesión feudal ex-post a la huida de Jizi (como indica el Shangshu Dazhuan)?23

Unos 800 años después, la historia contemporánea a la familia Sima, por su parte, comienza con la "Memoria de Chaoxian"24. Allí, Sima Qian nos cuenta que:

(Wei) Man, ${ }^{25}$ el Rey de Chaoxian, ${ }^{26}$ era un nativo del antiguo Yan. ${ }^{27}$ Empezando en tiempos de apogeo de Yan, éste invadió y controló a Zhenfan y Chaoxian, instaló allí funcionarios y construyó fortificaciones. ${ }^{28}$ Luego de que Qin aniquilara a Yan, tomó el control de la Comandancia de Liaodong ${ }^{29}$ y de sus regiones circundantes. Tras el ascenso de Han, (la Corte), considerando (a la región) como demasiado distante y difícil de defender, reconstruyó las viejas fortificaciones de Liaodong hacia el Río Pei ${ }^{30}$ como (nueva) frontera, y las puso bajo el control de Yan. ${ }^{31}$ Cuando Lu Wan, Rey de Yan, se rebeló y se unió a los Xiongnu, ${ }^{32}$ Weiman se exiló, reunió una banda de más de mil seguidores y, con el pelo

${ }^{23}$ La versión canónica del Shangshu sólo menciona el exordio de Jizi al Rey Wu, como se dijo, en "Hongfan" del Shangshu.

24 Shiji, 115 (Nienhauser, 2016, pp. 47-57). La traducción literal es "biografía de Chaoxian" (chaoxian liezhuan, 朝鮮列傳), y la sección pertinente del Shiji en la que está incluida (caps. 61-129) es, precisamente, "Biografías" (liezhuan, 列傳), una miscelánea de relatos biográficos reservada a personajes notables no incluidos en los Anales dinásticos (benji, 本紀) o a las familias hereditarias (shijia, 世家), a las cuales pertenece el capítulo 38 analizado ut supra. cf. Xu (2016, pp. 20-21). La traducción del equipo de Nienhauser que seguimos lee "memoria", Memoir, para las biografías. Asimismo, la colección dirigida por el traductor se titula Registros del Gran Escriba (The Grand's Scribe Records), en vez del más apropiado Memorias Históricas (Shiji). La traducción previa de Burton Watson (1993) también titula "Records" a diferencia de Édouard Chavannes (1967), fiel a la traducción literal.

${ }^{25}$ De la misma manera a lo señalado en n. 8, exponemos la traducción literal de Nienhauser, "(Wei) Man”. Cabe por ende aclarar que "(Wei) Man", "Weiman", y "Man" son la misma persona. En el original chino sistematizado y digitalizado por Sturgeon (2017b) se lee: 朝鮮王滿. Esto es, "Man, el Rey de Chaoxian": Shiji, 115,1. El pasaje corresponde al facsímil principal utilizado por Sturgeon (2017a, p. 180). Por otro lado, Nienhauser enfatiza un punto sobre el que volveremos en nuestra siguiente sección: "Algunos historiadores creen que Weiman era coreano y no chino Han, y esto ha inclinado a la historiografía contemporánea sobre la cuestión hacia líneas nacionalistas." (Nienhauser, 2016, p. 47, n. 2).

26 "Chaoxian bajo Weiman incluía a la mayor parte de Corea del Norte y a la mitad oriental de la actual Liaoning (...) Takigawa (...), citando a Nakai Sekitoku, señala que otras referencias pre-Han a Chaoxian son no necesariamente a un Estado, sino simplemente a un lugar, que se asumía como el mismo que el temprano feudo." (Nienhauser, 2016, p. 47, n. 3).

${ }^{27}$ En Shiji, 34, también se lee: “Shi 随,el Duque de Shao 召, tenía el mismo nombre que la (casa real) Zhou 周 [royal house], y el nombre de este clan era Qi 姬. Luego de haber destruido a Zhou 封 (xin), el Rey Wu 武 de Zhou enfeudó al Duque de Shao en Yan del Norte 北燕.” (Nienhauser, 2006, p. 169). “Yan del Norte" es la denominación dada aquí para Yan. Ver: Nienhauser (2006, p. 169, n. 3; Shaughnessy, 1999, pp. 312-313; Rawson, 1999, pp. 409-410).

${ }^{28}$ Alrededor del 285 a.C.

${ }^{29}$ Entre la actual provincia china de Liaoning, y el Norte de la Península Coreana.

${ }^{30}$ Basado en evidencias arqueológicas recientes, Nienhauser (2016, p. 48, n. 9) supone que el río Pei es el actual Ch'ong Ch'ong, al NO de la actual Pyongyang.

${ }^{31}$ El reino Yan establecido por Han, no el "viejo Yan": el reino Yan establecido por Han no incluía a Zhenfan ni a Chaoxian.

${ }^{32}$ Lu Wan y Liu Bang, el luego Emperador Gaozu (r. 206-195 a.C.), eran amigos cercanos que provenían de la misma aldea. Gaozu lo tenía en gran estima, "queriéndolo como a su propio hijo". Todo ello hasta que Gaozu, en sus últimos años, devino sospechoso de sus generales, incluyendo a Lu Wan. Cuando Gaozu 


\section{9 | Gustavo E. Santillán y José María Resiale Viano}

anudado y en ropas bárbaras, escapó hacia el Este más allá de las fortificaciones. Luego de cruzar el río Pei, ocupó las tierras otrora vacantes durante Qin y, moviéndose arriba y abajo a través de las fortificaciones, controló y subyugó gradualmente a los bárbaros en Zhenfan y Chaoxian, así como a los exiliados de los viejos Yan y Qi y se convirtió en Rey, ${ }^{33}$ estableciendo su capital en Wangxian. ${ }^{34}$

Ocurrió que durante la época del Emperador Xiaohui (r. 194-188 a.C.) y de la Emperatriz Regente Lü (241-180 a.C., r. 187-180 a.C.), cuando el Imperio recién había sido estabilizado, el Gran Administrador de Liaodong llegó rápidamente a un acuerdo con Man para convertirlo en un vasallo extranjero (de Han) ${ }^{35}$, para proteger a las tribus bárbaras residentes más allá de las fortificaciones (de frontera), pero no permitiéndoles que realizaran pillajes sobre la frontera (Han); y si varias jefaturas de las tribus bárbaras quisiesen entrar y prestar homenaje al Hijo del Cielo, Man no estaba autorizado a obstruirlas. (Cuando esto) fue informado, el Soberano lo aprobó. Por esta razón, Man, obteniendo poder militar, propiedades y bienes (de parte de Han), estuvo en condiciones de invadir y subordinar a sus ciudadelas (Xiaoyi, 小邑) vecinas. ${ }^{36}$ Zhenfan y Lintun ${ }^{37}$ cayeron bajo su control, alcanzando (las fronteras de Chaoxian) varios miles de li por cada lado. ${ }^{38}$

Cuando (Chaoxian) pasó a su hijo (de Weiman) y a su nieto (Wei) Youqu ${ }^{39}$, aquellos fugitivos de Han que fueron atraídos (a ir hacia Chaoxian) crecieron grandemente en número, y Youqu no fue más (a la Corte Han) a rendir homenaje. (Mientras tanto) Zhenfan y los Estados vecinos ${ }^{40}$ habían querido elevar memoriales (expresando el deseo de) rendir homenaje al Hijo del Cielo, pero Youqu les bloqueó también el paso, y no les dejaría llegar.

murió, en 195 a.C., Lu se rebeló y huyó hacia los Xiongnu. El episodio está narrado de manera sintética en los Anales de Gaodi del Han Shu, de Ban Gu (An y Zhang, 2015, pp. 101-105) Extensa y detallada, la biografía de Lu Wan consta en Shiji, 93 (Nienhauser, 2008, pp. 120-140).

33 "Weiman usurpó el trono de Chaoxian en el primer año de reinado del Emperador Hui de Han (194 a.C.). El Hou Han Shu (85: 2820) da más detalles: 'Anteriormente, el Rey Wu (de la Dinastía Zhou) enfeudó a Jizi en Chaoxian... más de cuarenta generaciones después, Chun, Marqués de Chaoxian, se proclamó Rey. Durante los desórdenes ocurridos a comienzos de la Dinastía Han, aquella gente de Yan, Qi y Zhao que había huido a Chaoxian eran decenas de miles, y un nativo de Yan, Weiman, atacó y aplastó al Rey Chun, proclamándose él mismo Rey de Chaoxian." (Nienhauser, 2016, p. 49, n. 15). Basándose en este último pasaje, algunos historiadores han dado por buena la continuidad entre el reino dirigido por Chun, y el linaje de Jizi. Cf. Xu (2016, p. 30). Como vimos, esto no consta en el Shiji.

34 Justo al Sur de la actual Pyongyang.

35 Waichen, 外臣. Esta relación implicaba el otorgamiento de autonomía política local, contra la prestación de tributo formal a la Corte Han (Nienhauser, 2016, p. 50, n. 17).

${ }^{36}$ Para precisar el alcance de la soberanía de Chaoxian bajo Weiman, Nienhauser cita un trabajo de Wang Liqi para el que no da referencias en la bibliografía: “Wang Liqi (115: n. 2427) cree que Weiman puede haber controlado partes de los tres Estados proto-coreanos de Zhenhan, Mahan, y Bianhan (cor. Byeonhan), que a su vez controlaban buena parte de la península coreana al sur de Chaoxian." (Nienhauser, 2016, p. 50, n. 18). Una interpretación alternativa, que reduce la soberanía de Chaoxian a la de una "ciudad Estado", en el trabajo de Gina Barnes (2001, pp. 3-15), que analizamos en nuestra sección siguiente.

${ }^{37}$ El mismo toponímico de dos de las futuras comandancias Han. Se caracteriza a Lintun como un Estado de la "tribu" de los Yi Orientales. Nienhauser, 2016, p.50, n. 19; Yu, 1986, p. 447.

${ }^{38}$ Nienhauser (2016, p. 50, n. 20) sostiene que la extensión de Chaoxian durante Weiman era de "1200 millas" de N a S.

${ }^{39}$ cor. Ugo

40 “El Hanshu (95: 3864) escribe en paralelo: 'Zhenguo'... por bangzhongguo (旁眾國, Estados vecinos). La anotación de Yan Shigu al Hanshu refiere a Zhenhan (震韓) un Estado localizado en lo que actualmente es la parte Sudeste de la península coreana... El Houhanshu (85: 2817) dice que el pueblo de Zhenhan reclamaba ser refugiado de la Dinastía Qin, y que su idioma era similar al de Qin. Su Estado era, de esta manera, denominado Qinhan (秦韓)" (Nienhauser, 2016, p. 51, n. 22).

Anuario de la Escuela de Historia Virtual - Año 9 - Nº 13 - 2018: pp. 1-23. ISSN 1853-7049 
10 | El Reino Wiman Joseon: aproximaciones y perspectivas...

A resultas de este diferendo, ocurrido en 109 a.C., el Emperador Wu (r.141-87 a.C.) nombra a un emisario, She He, para poner en vereda a Youqu. En camino, She He mata a un "soberano" ${ }^{41}$ subordinado a Chaoxian. A su regreso a la Corte Han, Wudi "premia" a She He con el cargo de Comandante al Este de Liaodong (en torno a la actual ciudad de Shenyang). Esto no hace más que agravar la tensión entre el Imperio y Chaoxian, desde donde Youqu decide un ataque sorpresa a la comandancia oriental de Liaodong. Este ataque termina con la vida de She He, tras lo cual Wudi lanza finalmente una ofensiva masiva sobre Chaoxian. ${ }^{42}$ La invasión logra la aniquilación del reino, y a partir de allí el Estado Han decide la división del territorio en cuatro Comandancias: Lelang (樂浪), Lintun (臨屯), Xuantu (玄菟) y Zhenfan (真番). La campaña se inició en 109 a.C. y concluyó en 108 a.C. Las tropas Han, de acuerdo con Sima Qian, estaban compuestas por más de 55.000 hombres. ${ }^{43}$

La conclusión de la memoria redactada por Sima Qian nos da a su vez más pistas para seguir el derrotero que comenzara en el reino de Yan y que concluyera en la conformacion de Chaoxian bajo Weiman. Sima Qian sintetiza su relato de la siguiente manera: “Cuando (el Heredero) Dan de Yan huyó raudamente hacia Liao, Man recogió a su gente, que había huido (allí), y los agrupó (a todos) al Este del Mar (Amarillo), congregándose así en Zhenfan y protegiendo las fortificaciones como un vasallo (externo)...."..$^{44}$

Entonces, para terminar de componer el cuadro histórico, comprimido por Sima Qian en su conclusión a la Memoria entre dos acontecimientos (la huida de Dan de Yan y la huida de Weiman hacia Chaoxian), debemos detallar el primero de estos eventos. El escape de Dan, que se inscribe en la campaña triunfal de Qin hacia la unificación imperial, es relatado por Sima Qian en la "Biografía de los Asesinos - Secuaces", particularmente en la biografía de Jingke (Shiji, 86)..$^{45}$ Jingke fue pues el asesino frustrado de Zheng de Qin (el futuro Qinshihuangdi) por encargo de Dan. Concretamente, Jingke fracasa en 227 a.C. en su intento de apuñalar (con una daga envenenada) a Zheng, evento que desemboca en 222 en el aniquilamiento definitivo del reino de Yan por la potencia emergente. De la siguiente manera:

Luego de esto (del intento fallido de asesinato), el Rey de Qin, en grande ira, envió refuerzos a Zhao y ordenó al Ejército de Wang Qian para que ataque a Yan junto a ellos. En el décimo mes, conquistaron Qizheng. Xi (喜), el Rey de Yan (r. 254-222 a.C.) y su heredero, Dan, condujeron a sus mejores tropas hacia el Este, y tomaron refugio en Liaodong (遼東). El General Li Xin de Qin persiguió y atacó vigorosamente al Rey de Yan. Jia (嘉), el rey de Dai (代), envió una carta a Xi, Rey de Yan. Allí se lee: ‘La razón por la

\footnotetext{
${ }^{41}$ Probablemente, un gobernante de una de las "ciudadelas" subyugadas por Weiman.

42 Nienhauser (2016, p. 51).

${ }^{43}$ Nienhauser (2016, p. 52).

${ }^{44}$ Nienhauser (2016, p. 57).

${ }^{45}$ Nienhauser (1994, pp. 332-333).
} 
cual Qin te persigue con tanto vigor, Yan, es a causa de Dan, tu heredero. Si Su Majestad mata a Dan y presenta (su cabeza) al Rey de Qin, el Rey de Qin va a dejarte libre con seguridad y, si tienes suerte, tus altares del suelo y de los granos podrán continuar recibiendo sus sacrificios de sangre.' Luego de esto, cuando Li Xin se encontraba en persecución de Dan, Dan se escondió en el Río Yan (衍水). El Rey de Yan mandó a un emisario para que corte la cabeza de Dan, con la intención de presentarla ante Qin. Qin envió más tropas para atacarlo. Cinco años después [222 a.C.], Qin finalmente destruyó a Yan y capturó a Xi, el Rey de Yan.

$\mathrm{Al}$ año siguiente [221 a.C.], Qin conquistó el mundo y estableció el título de "Emperador". Qin comenzó entonces a perseguir a los secuaces del Heredero Dan y de Jingke, y entonces todos ellos huyeron. ${ }^{46}$

Esta es pues una primera "huida" más allá de Liaodong, previa al escape de Weiman. Bien que protagonizada por élites del reino "antiguo" de Yan, constituye un antecedente a los sucesos de 194 a.C., ${ }^{47}$ y refuerza la evidencia de migraciones provenientes del espacio chino hacia la península coreana, de acuerdo al relato de Sima Qian. Si a esto sumamos el reconocimiento chino de un feudo, de naturaleza indeterminada, como vimos, en Chaoxian 800 años antes, es probable mantener la existencia de intercambios fluidos a lo largo de la frontera nororiental del espacio chino. ${ }^{48}$ En tercer lugar, en el Shiji se define a las entidades subyugadas por Weiman en Chaoxian como "ciudadelas" (Xiaoyi, 小邑), lo que permite inferir el reconocimiento de algún grado de complejidad social y organizativa en la región. El significado de los caracteres es el siguiente: 小 es evidentemente “pequeño” y 邑, “ciudad”. Etimológicamente, el radical 邑 (163, UC 1.1) se descompone a su vez en $\square$, wei, muralla, y ए, jie, sello, símbolo de la autoridad administrativa (Karlgren, 1973, 194, p. 82). De allí el carácter de la polémica señalada ut-supra (p. 9, n. 36) entre quienes, como Nienhauser, sostienen que Chaoxian fue un reino impuesto sobre "Estados proto-coreanos" y quienes, como Gina Barnes, reducen a Chaoxian a una "ciudad-estado" más, de las existentes en el área.

De cualquier manera, tomando estos elementos, es posible mantener a) la existencia de cierta complejidad administrativa, b) el contacto permanente entre el espacio chino y sus fronteras, y c) la temprana influencia china en la región ${ }^{49}$, bien antes de la invasión Han y de la instalación de comandancias militares en la península coreana.

Esto último queda ejemplificado finalmente en dos elementos: por un lado, a partir

\footnotetext{
${ }^{46}$ Nienhauser (1994, pp. 332-333).

47 Para los especialistas de la Historia de China de la Universidad de Cambridge, 195 a.C.; Yu (1986, p. 448). ${ }^{48}$ Durante el siglo IV a.C., por ejemplo, "contactos comerciales activos estaban llevando a algunos de los habitantes de Yen hacia Corea, donde dejaron grandes cantidades de moneda acuñada por Yen. Los términos de intercambio, o el tipo de artículos transados, no pueden especificarse.": Yu (1986, p. 447). (Wade Giles en el original).

49 “Las tribus con las que Chi-tzu u otros aventureros chinos pueden haberse encontrado, podrían haber sido ancestros de los pueblos conocidos como los Puyo (Fu-yii), alrededor del río Sungari, los Ok-cho (Wu-chii), quienes parecen haber estado centrados alrededor del paralelo 40, o bien los Wei-mo, quienes vivían más al sur, alrededor del centro de la península. Poco puede ser dicho acerca de la afiliación étnica de estos pueblos, o de algunos rasgos distintivos a través de los cuales podrían ser caracterizados.": Yu (1986, p. 447). (Wade Giles en el original) (el subrayado es nuestro).
} 
12 | El Reino Wiman Joseon: aproximaciones y perspectivas...

de Weiman es probable, de acuerdo a los sinólogos, que la introducción de artículos de hierro chinos hayan incentivado la industria local de este material ( $\mathrm{Yu}, 1986$, p. 448). Por otro lado, existe evidencia de la circulación temprana de la moneda en forma de cuchillo del reino de Yan, en una amplia zona geográfica que atañe a la región analizada (Kakinuma, 2014, pp. 79-126).

\section{Joseon en los Estudios Coreanos}

Estudiar la formación y características del reino Joseon de Wiman implica, al mismo tiempo, inmiscuirse en las formulaciones acerca de los primeros Estados en la península coreana. En este sentido, existe una amplia discusión en torno de ambos procesos, interviniendo en ella tanto la evidencia empírica -restos arqueológicos y textos antiguos que no siempre coinciden en sus relatos- como los intentos nacionalistas que pretenden formular y fortalecer el origen de esa nación más allá de la evidencia concreta, recurriendo a explicaciones mitológicas.

De esta manera, en este segmento revisaremos las formulaciones acerca del origen y carácter del Estado Joseon presentes en la bibliografía especializada sobre Corea. En esta línea, debemos comenzar haciendo dos advertencias: en primer lugar, que no existe historia escrita de Corea hasta los siglos inmediatamente anteriores a la era cristiana, y que esa historia fue cronicada por los escribas chinos (Xu, 2016, pp. 3, 5-6). En segundo lugar, la información proporcionada por los datos arqueológicos no ha sido integrada en las explicaciones sobre la formación del Estado coreano, que se sustentan principalmente en los textos históricos (Barnes, 2001, p. 8). En este sentido, las fuentes escritas coreanas más importante sobre los Estados tempranos en la península provienen de dos historias: el Samguk Sagi (Historia de los tres Reinos) y el Samguk Yusa (Memorabilia de los tres Reinos), compilados en 1145 por Kim Bu-sik y en 1279 por el monje budista Iryeon, respectivamente, mucho tiempo después de los acontecimientos que rela$\tan$ (Barnes, 2001, p. 2; Seth, 2010, p. 16; Xu, 2016, pp. 5-6). Ambas obras, evidentemente, pretenden parangonarse desde su título a la Crónica de los Tres Reinos china. El Samguk Yusa, amén de referirse al mito de Dangun (cf. infra, pp. 13-15) contiene una reescritura de la crónica de Chaoxian narrada por Sima Qian, y coherente con ella (Gardiner, 1969, p. 10).

Existe consenso entre los especialistas sobre que los humanos habitaron la península coreana durante el neolítico. Estas sociedades llegaron a construir ciudades amuralladas, fabricaron instrumentos de piedra y madera, y dominaron incluso el bronce (Ebrey, Watlhall y Palais, 2009, pp. 98-99; Kim, 2012, p. 11; Lee, 1984, p. 14). Entre los años 6.000 y 2.000 a.C. se habría producido un período de transición de la caza, pesca y recolección a la agricultura como base de la subsistencia. La agricultura temprana probablemente habría sido introducida por el arribo de migrantes provenientes del centro y sur de China (Seth, 2010, p. 11). 
El disenso aparece cuando se intenta situar la aparición de la primera organización estatal en la península. En este sentido, existen diferentes formulaciones y argumentos, pero cuatro entidades estatales diferentes parecen cristalizar el surgimiento del Estado: Dangun Joseon (단군조선), Gija Joseon (기자조선), Wiman Joseon (위만조선) y los reinos de Silla (시라), Goguryeo (고구려) y Baekje (백제). El desacuerdo entre los historiadores de Corea se manifiesta desde el mismo momento en que, mientras algunos consideran a estos Estados como parte de una única sucesión lineal, otros ven el origen del Estado sólo en uno de ellos o los consideran como entidades diferentes que podrían haber coexistido. En este marco, realizaremos una revisión de los potenciales primeros Estados coreanos hasta concentrarnos en el caso de Wiman Joseon.

\section{Dangun Joseon}

Está muy extendido entre los coreanos la idea de que ellos pertenecen a una "raza homogénea" (tan'il minjok, 단일민족) que se extiende hasta tiempos prehistóricos (Pai, 2000, p. 57). ${ }^{50}$ La homogeneidad de la población estaría asegurada al considerar que el pueblo coreano desciende en su totalidad de una única persona, Dangun (단군). La difusión de la conciencia de los coreanos como “descendientes de Dangun" se llevó adelante a través de los libros de historia y los medios de comunicación entre finales del siglo XIX y principios del XX (Kim, 2014, p. 214; Guex, 2012, pp. 131-138). Esta historia de Dangun procede de un antiguo texto perdido que data del siglo III a.C., llamado Dangun Kogi (El registro antiguo de Dangun y su dinastía); sin embargo, el texto es citado en obras posteriores escritas entre los siglos XIII y XIV, siendo la más conocida el Samguk Yusa (Seligson, 2003; Gardiner, 1969, pp. 3-11).

Según la leyenda, el hijo del Señor Supremo del Cielo (Hwanung) descendió a la tierra sobre el monte Baekdusan (백두산), en el norte de la península coreana. Allí, se relacionó con un oso convertido en mujer (Ungnyo), y juntos concibieron a un hijo llamado Dangun. Este habría fundado en el año 2333 a.C. el reino de Joseon (조선) o Gojoseon (고조선) ${ }^{51}$, gobernando durante más de 1000 años.

La leyenda de Dangun fue popularizada por los historiadores nacionalistas en el marco de la dominación colonial japonesa sobre Corea con el fin de encontrar un símbolo nacional de consolidación política (Seligson, 2003).52 En este sentido, podríamos nombrar los casos de algunos estudiosos coreanos que pretendieron interpretar la his-

\footnotetext{
${ }^{50}$ De acuerdo a Guex (2012, p. 132), el término "minjok" (민족) apareció por primera vez en Japón (minzoku), ofreciéndole a los historiadores coreanos una poderosa herramienta para reescribir el pasado; de esta manera, la genealogía del linaje coreano podía remontarse hasta la figura de Dangun.

${ }^{51}$ A continuación, el reino de Gojoseon y “Antiguo Joseon" constituyen la misma entidad.

${ }^{52}$ Los regímenes de Rhee y Park, de acuerdo con Guex (2012, p. 132), optaron por apoyar las narrativas de los historiadores nacionalistas basadas en la idea de la homogeneidad étnica y en la fundación mítica del Estado por Dangun, para legitimar sus posiciones, intentando identificar el nacionalismo con el anticomunismo, en tanto que los historiadores comunistas serían los responsables de haber completado una larga historia de Corea como una nación unitaria.
} 
14 | El Reino Wiman Joseon: aproximaciones y perspectivas...

toria de Corea a la luz de Dangun. En esta línea, uno de los primeros defensores de la importancia histórica de Dangun fue Sin Ch'ae-ho (1880-1936), quien es considerado en Corea como uno de los historiadores nacionales más importantes. Sin consideraba que la historia de Corea se inicia con Dangun y que éste habría gobernado en una sociedad de jefaturas, concentrando el poder político y religioso (Pai, 2000, pp. 63-64).

Otro historiador muy reconocido, Ch'oe Nam-seon (1890-1957), fue aún más lejos que Sin. Ch'oe desarrolló la "Teoría de la cultura de Pulham" (Pulham derivaría de Pulhamsan, antiguo nombre de Baekdusan), en la cual sostenía que la cultura del Este Asiático tenía su origen en Dangun. La teoría se basaba en la "evidencia lingüística de los topónimos": con sílabas similares en sonido al adjetivo "Palg" (밝), que es la palabra raíz de "luz" o "brillo" en Corea, una pronunciación similar indicaba que los nombre de lugares y civilizaciones remotos tenían todos origen en la misma fuente. Dentro de la esfera cultural de Pulham, por lo tanto, se encontraría una amplia área geográfica que llegaría hasta los Balcanes (Pai, 2000, pp. 66-68).

Un tercer investigador relevante es Kim Chae-won, quien sostuvo que había encontrado la única evidencia arqueológica sobre la existencia de Dangun en la península de Shandong; se trataba de grabados sobre un santuario de la familia $\mathrm{Wu}$ realizado en tiempos de la dinastía Han. Entre varias figuras talladas sobre diferentes losas que conformaban el santuario, Kim había encontrado algunas escenas que interpretó como la representación del arribo de Hwan'ung y como el nacimiento de Dangun. De esta manera, estas escenas significaban para el autor la versión china de la leyenda de Dangun. Esta teoría postulada por Kim recibió numerosos adeptos. Sin embargo, no estuvo libre de críticas: en primer lugar, porque el autor interpretaba algunas escenas de manera aislada, sin considerar el resto de la obra; de esta manera, habría descontextualizado las escenas. En segundo lugar, Kim dejaba muchas preguntas sin resolver, como, por ejemplo, cuándo, dónde y a partir de qué fuente se había originado la leyenda de Dangun (Pai, 2000, pp. 71-73).

De esta manera, la historia de Dangun fue recogida por algunos especialistas coreanos en un momento particular de la historia de la península, siendo funcional al nacionalismo coreano. En esta línea, el Estado habría surgido en Corea de manera independiente, sin ninguna conexión con los países vecinos y con anterioridad a la dinastía china Xia (s. XXI a XVI a.C.); como sostiene Cumings, la leyenda de Dangun se ha constituido en el origen mítico del Estado coreano, y la conformación de los Estados subsiguientes a Dangun Joseon aseguraría la "pureza racial", la homogeneidad del pueblo coreano y el desarrollo autónomo del Estado en la península (Cumings, 2004, p. 26).

Sin embargo, este relato no deja de ser una leyenda que recurre al mito para explicar los orígenes del pueblo coreano y, por lo tanto, no puede ser considerado como cierto. De este modo, esta recurrencia de ciertos historiadores nacionalistas coreanos al mito puede calificarse como anacrónica, aún en el contexto de formulación de su tiempo. A pesar de ello, la imagen de Dangun sigue todavía presente en la cultura coreana: por 
ejemplo, en 1993 se anunció en Corea del Norte que se habían descubierto restos óseos, y que serían de Dangun; no obstante, sostiene Cumings, estos hallazgos parecen poco creíbles (Cumings, 2004, p. 26; cf. Xu, 2016, p. 8). Por lo tanto, aunque la historia de Dangun es un elemento constitutivo muy importante de la cultura coreana, dado su carácter de explicación mitológica sobre la fundación del Estado, carece de valor en términos históricos.

\section{Gija Joseon}

La segunda formación estatal en discusión es Gija Joseon (ch. Jizi Chaoxian). La historia de Gija (단군) proviene, como establecimos, del Shangshu, el Shangshu Dazhuan y el Shiji. La presencia de Gija en la historia coreana ha suscitado diferentes posturas al respecto. Al parecer, refugiados de la provincia de Shandong se habrían asimilado a la población local de la región de Manchuria, floreciendo una nueva cultura conocida como Gija Joseon. Así, mientras China atravesaba un momento de turbulencia política, Gija Joseon habría florecido durante casi 800 años (Lee, 2013, p. 416). Hasta el siglo XX, los coreanos creían que Dangun había concedido a Corea su pueblo y cultura básica, mientras que Gija le proporcionaba una "alta cultura" y la legitimidad, al ser reconocida por China; de este modo, se aseguraría la conexión entre la población y cultura coreana con la población y cultura china (Kyung, 2010, p. 22; Gardiner, 1969, p. 10).53 Gardiner advierte que un mojón incontrastable de la influencia china sobre la península está constituido por la posterior introducción de artefactos metálicos (armas de hierro y de bronce) desde el espacio chino, ocurrida a partir del siglo III a.C. (Gardiner, 1969 , p. 7). Lo mismo vale para la introducción de monedas en forma de cuchillo procedentes del reino de Yan, mencionada también por Gardiner, lo que refuerza la tesis señalada en nuestra sección anterior. Más aún: “El comienzo del trabajo de los metales en Corea, a distinguirse respecto a la importación de artefactos de metal, debería estar asociado probablemente al ascenso del reino de Choson de Weiman (sic) o, con mayor propiedad, al influjo de refugiados chinos, quienes jugaron un papel preponderante en la creación del nuevo Estado." (Gardiner, 1969, p. 8).

No obstante, con posterioridad a la obra de Gardiner, Lee Ki-baik antedata el surgimiento de una cultura del hierro en Corea hacia la época de Gija, bien que influenciada por China. Sin embargo, sería erróneo suponer que el manejo del hierro en la pe-

\footnotetext{
${ }^{53}$ En este sentido, la historia de Gija fue tan importante durante los siglos previos al despertar nacionalista que los literatos de la Dinastía Joseon (1392-1910) afirmaban con orgullo que ellos eran los únicos portadores de la civilización china en el este de Asia, después de que los manchúes establecieran la dinastía Qing (1644-1912) (Xu, 2012, p. 16). En esta línea, Gija se había constituido en un vínculo ancestral clave con la antigua China, y fue venerado durante más de cinco siglos como el primer rey de Joseon que llevó la civilización a Corea (Guex, 2012, p. 142). En este contexto, se habría erigido un templo dedicado a Gija en el sitio en donde supuestamente se encontraba su tumba, el cual habría sido muy visitado por los viajeros que atravesaban la región (Portal, 2005, p. 80).
} 
16 | El Reino Wiman Joseon: aproximaciones y perspectivas...

nínsula coreana se desarrolló al compás de la implantación del dominio político de Gija, en tanto Lee Ki-Baik sostiene que se han encontrado numerosos moldes de fundición de bronce y hierro en la región. Esto sugiere para el autor que la "cultura del metal" tuvo un desarrollo autóctono. Por lo tanto, advierte Lee Ki-Baik, habría que tener cuidado a la hora de pretender explicar la influencia cultural de China en el manejo de los metales sobre Corea a través del arribo de Gija a la península (Lee, 1984, pp. 15-16).

Con el despertar de los sentimientos nacionalistas, el relato de Gija se fue ausentando de las explicaciones históricas (Kyung, 2010, p. 22). En este sentido, el ya mencionado Sin Ch'ae-ho descartaba que Gija fuera un sucesor directo de Dangun, porque esto habría significado que Corea había sido dominada por inmigrantes chinos desde tiempos remotos (Pai, 2000, p. 64) ${ }^{54}$ Hasta el momento, según sostiene Lee Mosol, la única evidencia que podría arrojar luz sobre Gija Joseon son las famosas monedas en forma de cuchillo, extendidas hasta Manchuria y el norte de la península coreana (Lee, 2013, p. 416). Como vimos, esto está mencionado también en la literatura sobre China. Sin embargo, para Ebrey, Walthall y Palais la existencia de Gija sólo se encuentra relatada en las fuentes escritas, y no se ha encontrado evidencia arqueológica que permita demostrar una implicación tan temprana entre Corea y el heartland chino (Ebrey, Walthall y Palais, 2009, p. 100).

\section{Wiman Joseon}

Siguiendo el orden cronológico, Wiman Joseon es la tercera formación estatal a considerar. La mayoría de los especialistas consideran a Wiman (위만) de acuerdo a lo señalado en las crónicas de Sima Qian, pero no existe para ellos evidencia arqueológica que permita comprobar su existencia.

En este sentido, los especialistas en estudios coreanos estipulan lo narrado en la sección anterior de la siguiente manera: se sostiene que Wiman era un hombre proveniente de Yan, y que cuando Yan comenzó un enfrentamiento armado contra los Xiongnu, Wiman decidió huir con mil seguidores hacia Joseon, donde el gobernante Chun le nombró comandante de frontera. Posteriormente, Wiman se habría rebelado contra el rey Chun con la ayuda de los chinos, que ya se habían asentado en Joseon, para establecerse él mismo como rey, en algún momento entre 194 y 180 a.C. (Seth, 2010, p. 17). De este modo, en un momento de convulsión política, Wiman habría "usurpado" el trono de Antiguo Joseon. (Lew, 2000, p. 6). ${ }^{55}$ Wiman, así como sus sucesores, habría servido como vasallo de China, actuando como intermediario entre los chinos y los pueblos tribales de la zona. Sin embargo, Wiman Joseon se habría constituido también en un lugar de exilio para los disidentes en la parte noreste del imperio Han. En este

\footnotetext{
${ }^{54}$ En los libros de historia escolares Gija no es mencionado en los más recientes textos publicados, manteniéndose de este modo la perspectiva nacionalista (Guex, 2012, p. 142).

${ }^{55}$ Esta interpretación, como vimos, abreva en el Hou Han Shu (cf. n. 33).
} 
sentido, el emperador Wu (141-87 a.C.) de la dinastía Han habría tratado de poner bajo control directo las regiones fronterizas del imperio, y habría conquistado al problemático reino Wiman Joseon (Seth, 2010, p. 17).

En esta línea, Lee Ki-Baik sostiene que la relación entre Wiman Joseon y los Han se fue desgastando con el tiempo. Wiman Joseon creció en fuerza y tamaño sojuzgando a Estados vecinos, prohibiendo a estos Estados más pequeños tener contacto directo con los Han, y buscando así beneficiarse como un intermediario en el área de comercio de China. Además, el Imperio chino temía por la amenaza que significaba la posibilidad de vínculos entre Wiman y los Xiongnu. Este es para Lee Kee-Baik el contexto de la caída de Wiman Joseon ante los Han en 108 a.C., cuando se instalaron las cuatro comandancias chinas.

Más allá de esta coincidencia sobre el final de Wiman Joseon, Lee Ki-Baik advierte que la identidad de ese Estado está aún en debate, en tanto la idea que sostiene que Wiman Joseon representó un régimen colonial gobernado por poblaciones chinas migrantes ha sido desafiada por numerosos eruditos. En este sentido, se argumenta que, en primer lugar, es probable que Wiman no haya sido un hombre de Yan, porque no habría llevado coleta y se habría vestido al estilo Joseon cuando con sus seguidores ingresa a Antiguo Joseon. Al respecto, como vimos, Sima Qian sólo establece que "Weiman se exilió, reunió una banda de más de mil seguidores y, con el pelo anudado y en ropas bárbaras, escapó hacia el Este más allá de las fortificaciones", dando a entender que se trataba de un "disfraz" necesario para garantizar la huida. Si esto es así, o si el ropaje de Wiman era un indicio de su adscripción como oriundo de la península coreana, resulta una cuestión de interpretación sobre la fuente histórica. En segundo lugar, Lee Ki-Baik añade que Wiman continúa utilizando "Joseon" para nombrar a su reino; en tercer lugar, muchos hombres del Antiguo Joseon ocupan cargos importantes bajo el gobierno de Wiman. ${ }^{56}$ De esta manera, a partir de estas consideraciones, algunos especialistas sugieren que aunque Antiguo Joseon haya confiado en los conocimientos más sofisticados de la "cultura del hierro" que aportaban los migrantes chinos, ello no es razón suficiente para sostener que Wiman Joseon haya sido simplemente un régimen colonial chino (Lee, 1984, p. 17).

\footnotetext{
56 Para el historiador Yi Pyŏngdo, el peinado de Wiman y la vestimenta bárbara que usaba cuando huyó a Corea, la continuidad del nombre de Joseon para el nuevo Estado, y la resistencia que el reino ofrece contra la invasión Han, constituyen evidencia suficiente para decir que Wiman no era un emigrado, sino más bien un descendiente de Antiguo Joseon. Esta línea interpretativa fue adoptada a la hora de enseñar historia de Corea en las escuelas, y Wiman fue elevado al rango de héroe nacional al dirigir a sus compatriotas contra la invasión Han (Xu, 2012, p. 17). En la misma línea, Guex (2012, p. 144) sostiene que en los textos escolares de historia Wiman está completamente integrado como un gobernante coreano y se presenta como un sucesor legítimo de Antiguo Joseon, contrariamente a Gija. De esta manera, a partir de una interpretación libre del relato de Sima Qian (en tanto que éste menciona que Wiman portaba "ropas bárbaras"), y el Samguk Yusa (en donde no se hace mención al origen étnico), se ha producido un intento de coreanización de Wiman. De este modo, se aseguraría la continuidad y profundidad en el tiempo del Estado coreano.
} 
18 | El Reino Wiman Joseon: aproximaciones y perspectivas...

Por su parte, Keith Pratt, quien no menciona a Gija Joseon, sostiene que la población de Wiman Joseon provenía tanto desde el este, como del oeste y norte y, por lo tanto, que no podría definirse como un Estado coreano ni tampoco chino (Pratt, 2007, p. 34). Por lo tanto, más allá de ubicarse en la península coreana, la procedencia de su gente no haría de Wiman Joseon un Estado propiamente coreano; además, esto invalidaría completamente la idea de la homogeneidad del pueblo coreano. En esta misma línea, Holcombe (2001, p. 166) afirma que se podría suponer que Wiman no se consideraba a sí mismo como "coreano" ni como "chino"; el autor añade además que el actual pueblo coreano es descendiente de diversos pueblos prehistóricos que habitaban la península coreana y el núcleo cultural de la Llanura Central. De este modo, los mencionados aportes de Pratt y Holcombe contribuirían a reforzar la idea de que la región norte de la península coreana constituía un ámbito de permanente flujo migratorio e intensos intercambios culturales.

De manera contraria a quienes consideran las diferentes formaciones estatales que hemos revisado como una sucesión lineal en el tiempo, Lee Mosol sostiene que los historiadores coreanos actuales llaman a estos tres reinos como Antiguo Joseon, sin ninguna demarcación específica clara. De acuerdo al autor, existe evidencia histórica que muestra que aquellos tres reinos cambiaron el liderazgo uno tras otro, pero que cada reino podría tener fronteras territoriales diferentes (Lee, 2013, p. 414). ${ }^{57}$ De esta manera, a pesar de llevar el nombre de Joseon, estos Estados podrían no tener relación directa entre ellos. En este sentido, vale recordar que en las fuentes chinas el nombre asociado desde temprano con Corea, "Chaoxian", significaría "Tierra de la calma de la mañana" (chao significa "amanecer" o "mañana", y xian significa "fresco" o "calma") (Seth, 2010, p. 17). ${ }^{58}$ De este modo, las alusiones a Chaoxian/Joseon no necesariamente pueden referirse a un Estado, sino también a un espacio geográfico determinado, generándose entonces confusiones entre ambos.

Llegados este punto, Michael Seth señala que, aunque las historias coreanas sostienen la creación del Joseon en 2333 a.C. y su continuidad en el tiempo a través de diferentes sucesores, de acuerdo a la evidencia empírica, sólo a partir de la invasión Han y la instalación de las cuatro comandancias puede constatarse en la región la existencia de una entidad política llamada Joseon (Seth, 2010, p. 17). ${ }^{59}$ De este modo, para Seth no se deberían considerar las formaciones estatales descritas arriba hasta no contar con evidencia suficiente. Por su parte, Barnes define a Dangun Joseon, Gija Joseon y Wiman

\footnotetext{
57 Esta "secuencia dinástica" de Dangun Joseon - Gija Joseon - Wiman Joseon fue el resultado de la división de Antiguo Joseon en tres momentos históricos, realizada durante la primera mitad del siglo XX (Guex, 2012, p. 137).

${ }^{58}$ Según el autor, el nombre provendría de la posición geográfica, en tanto Corea, en relación a China, se ubicaba al este, siendo un país "temprano de la mañana", así como Japón, más al este, fue designado "origen del sol".

${ }^{59} \mathrm{El}$ autor señala que todo lo relacionado a Joseon aún no está claro, pero sostiene que probablemente Joseon haya sido más un federación tribal que un Estado.
} 
Joseon, siguiendo a Gardiner, como tres mitos fundadores de una entidad estatal en Corea. En este sentido, afirma que el examen histórico de Joseon como un Estado debe comenzar a partir de la invasión Han de la península (en tanto existe evidencia irrefutable sobre este acontecimiento), y a partir de allí retroceder hacia el pasado a través de los datos arqueológicos (Barnes, 2001, pp. 10-12).

Entretanto, el descubrimiento reciente de tabletas de madera en Corea del Norte arrojó nueva luz sobre la historia de la comandancia de Naglang (ch. Lelang), y de Antiguo Joseon. Algunas de las tablillas contenían, en efecto, información sobre un censo realizado en Naglang, que registraba la existencia de 25 condados y una población de 280.561 habitantes en el año 45 a.C. A partir de datos proporcionados por estos descubrimientos, los hallazgos definirían a Antiguo Joseon como una etapa temprana en la formación estatal, y con una pequeña población comparable a una jefatura $(X u, 2012$, p. 18).

A modo de síntesis del apartado, de acuerdo a los textos más contemporáneos, sólo podríamos hablar de la existencia de un Estado desde el momento en que los Han extienden su dominio político hasta el norte de la península coreana, en tanto que la conquista se llevó adelante en detrimento de un Estado llamado Joseon, cuyo gobernante decía ser descendiente de Wiman, aunque esto aún no pueda ser comprobado. De este modo, el acceso al conocimiento de entidades estatales anteriores a la instalación de las cuatro comandancias sólo es posible a través de los diversos relatos escritos, aunque por el momento no pueden contrastarse con otro tipo de evidencia empírica. En esta línea, sólo podríamos convenir, de acuerdo al estado de la cuestión en Estudios Coreanos, que en los tiempos previos a la conquista del "Estado de Joseon" por los Han, existían en la península coreana algunas ciudades estados amuralladas, con algún nivel de diferenciación social y manejo de herramientas de bronce y hierro, habida cuenta del descubrimiento de rejas de arado, dagas, etc.

A pesar de ello, el mito de Dangun y la supuesta sucesión de su reino a través de diferentes gobernantes han permitido extender sobre la población coreana la idea de una "homogeneidad racial" perpetuada a través de los siglos, garantizando además la "pureza sanguínea", al no existir supuestamente relación con los pueblos vecinos. Ambos argumentos se constituyeron en los pilares del nacionalismo coreano de fines del siglo XIX y principios del XX. En este punto, la historia de Gija es problemática: por una parte, reconocer a Gija como gobernante de Joseon habría permitido, en algún momento, elevar la cultura de Joseon al nivel de la cultura china; pero, por otro lado, reconocer a Gija echa por tierra la idea de la homogeneidad coreana, en tanto habría que reconocer la porosidad de la frontera de Joseon, las continuas migraciones, y el permanente intercambio entre diferentes poblaciones en la región. En este mismo sentido, reconocer a Wiman como un emigrado chino plantea el mismo problema para el nacionalismo coreano. 
20 | El Reino Wiman Joseon: aproximaciones y perspectivas...

\section{Conclusiones}

Del examen realizado, debemos destacar en primer lugar el contraste entre las características de las fuentes escritas chinas y coreanas, dado que las primeras anteceden a las segundas. En este sentido, puede decirse que la historiografía coreana, clásica y moderna, ha estado condicionada por la cercanía de la civilización china primero y, luego, por el dominio y la ocupación japonesa. En segundo lugar, podemos rescatar algunos elementos expuestos en nuestro trabajo que nos permiten sostener la evidencia recurrente de intercambios tempranos entre el mundo chino y la península coreana. Destacan entre ellos la industria del hierro, la circulación de monedas o "protomonedas", las migraciones humanas, y la urbanización de la región. Ello no supone, por otro lado, mantener la linealidad sucesiva de Estados que tanto preocupó a la historiografía coreana: así, las continuidades entre Dangun Joseon, Gija Joseon y Wiman Joseon pueden legítimamente ponerse en duda. Al mismo tiempo, debemos poner de relieve la oscuridad del periodo que media entre la enfeudación de Jizi en Chaoxian y la asunción de Weiman como monarca en las fuentes chinas. Se trata de un periodo de 800 años sobre el que el Shiji no nos aporta información.

Finalmente, debemos poner de relieve las diferencias detectadas entre los estudios sinológicos, que dan un crédito mayor a las Memorias Históricas, y los Estudios Coreanos. Allí, tras un fuerte auge de interpretaciones nacionalistas, que termina de alguna manera en la obra de Lee Ki-baik, asistimos a un consenso contemporáneo que impugna aún la existencia misma del Estado Joseon en la península con anterioridad a la invasión Han.

\section{Referencias bibliográficas}

An, P. y Zhang, C. (Eds.) (2015). Chronicles of the Han Dynasty. Beijing: Foreign Languages Press.

Barnes, G. L. (2001). State formations in Korea. Historical and archaeological perspectives. Surrey: Curzon Press.

Chavannes, E. (1967). Les Mémoirs Historiques de Se-ma Tsien. París: Librairie d' Amérique et d' Orient, 6 vols.

Cheng, A. (2002). Historia del pensamiento chino. Barcelona: Bellaterra.

Cohen, R. (1978). State Origins: A Reappraisal. En H. J. M. Claessen y P. Skalnik (Eds.), The Early State (pp. 31-75). La Haya: Mouton Publishers.

Cumings, B. (2004). El lugar de Corea en el Sol. Una historia moderna. Córdoba: Comunicarte.

Ebrey, P., Walthall, A. y Palais, J. (2009). Pre-Modern East Asia to 1800. A cultural, social and political history. Boston/Nueva York: Houghton Mifflin Company. 
Engels, F. (2017). El origen de la familia, la propiedad privada y el Estado. Madrid: Akal.

Guex, S. (2012). Overcoming the frame of national history in South Korea. En R. Caroli

y P. Souyri (Eds.), History at stake in East Asia (pp. 131-154). Venecia: Libreria Editrice Cafoscarina.

Gardiner, K. (1969). The Early History of Korea. The Historical Development of the Peninsula up to the Introduction of Buddhism in the Fourth Century A.D. Canberra: Australian National University Press.

Harper, D. (1999). Warring States Natural Philosophy and Occult Thought. En M. Loewe y E. Shaughnessy (Eds.), The Cambridge History of Ancient China. From the Origins of Civilization to 221 B.C. (pp. 813-885). Cambridge: Cambridge University Press.

Holcombe, C. (2001). The genesis of East Asia 221 B.C.-A.D. 907. Honolulu: University of Hawaii Press.

Kakinuma, Y. (2014). The Emergence and Spread of Coins in China from the Spring and Autumn Period to the Warring States Period. En P. Bernholz y R. Vaubel (Eds.), Explaining Monetary and Financial Innovation. A Historical Analysis (pp. 79126). Nueva York: Springer.

Karlgren, B. (1973). Analytical Dictionary of Chinese and Sino-Japanese. Taipei: ChengWen Publishing Company.

Kim, J. (2012). A history of Korea. From "Land of the Morning Calm" to states in conflict. Bloomington/Indianapolis: Indiana University Press.

Kim, S. (2014). The Modern Korean Nation, Tan'gun, and Historical memory in Late Nineteenth to Early Twentieth Century Korea. International Journal of Korean History, 19 (2), 213-238.

Kyung, M. H. (2010). A history of Korea. An episodic narrative. Nueva York: Palgrave Macmillan.

Lee, K.B. (1984). A new history of Korea. Cambridge (Ma.): Harvard University Press.

Lee, M. (2013). Ancient history of the Manchuria. Redefining the Past. Estados Unidos: XLibris.

Lew, Y. (2000). Brief history of Korea. A bird's-eye view. New York: The Korea Society.

Legge, J. (Ed.) (1861). The Chinese Classics, vol I. Hong Kong-Londres: Trübner \& Co.

Lenin, V. I. (1987). Sobre el Estado. En J. C. Portantiero y E. De Ipola (eds.). Estado y sociedad en el pensamiento clásico (pp. 314-335). Buenos Aires: Cátaro.

Loewe, M. (2011). Dong Zhongshu, a 'Confucian' Heritage and the Chunqiu fanlu. Leiden: Brill.

Nienhauser, W. (Ed.) (2016). The Grand Scribe's Records. vol. X. The Memoirs of Han China - part III. Bloomington-Indianapolis: Indiana University Press.

Nienhauser, W. (Ed.) (2008). The Grand Scribe's Records. vol. VIII. The Memoirs of Han China - part I. Bloomington-Indianapolis: Indiana University Press.

Nienhauser, W. (Ed.) (2006). The Grand Scribe's Records. vol. V.1. The Hereditary Hous- 
22 | El Reino Wiman Joseon: aproximaciones y perspectivas...

es of Pre-Han China - part I. Bloomington-Indianapolis: Indiana University Press.

Nienhauser, W. (Ed.) (1994). The Grand Scribe's Records. vol. VII. The Memoirs of PreHan China. Bloomington-Indianapolis: Indiana University Press.

Nivison, D. (1999). The Classical Philosophical Writings. En M. Loewe y E. Shaughnessy (Eds.). The Cambridge History of Ancient China. From the Origins of Civilization to 221 B.C. (pp. 745-813). Cambridge: Cambridge University Press.

Nylan, M. (2001). The Five "Confucian" Classics. Chelsea: Yale University Press.

Pai, H. (2000). Constructing "Korean" Origins. A critical review of archaeological, historiography, and racial myth in Korean state-formation theories. Cambridge (Ma.): Harvard University Press.

Peterson, M. y Margulies, P. (2010). Brief history of Korea. New York: Infobase Publishing.

Portal, J. (2005). Art under control in North Korea. Londres: Reaktion Books.

Pratt, K. (2007). Everlasting Flower: a history of Korea. Londres: Reaktion Books.

Rakita Golding, P. (2001). The Thirteen Classics. En V. Mair (Ed.), The Columbia History of Chinese Literature (pp. 86-97). Nueva York: Columbia University Press.

Rawson, J. (1999). Western Zhou Archaeology. En M. Loewe y E. Shaughnessy (Eds.), The Cambridge History of Ancient China. From the Origins of Civilization to 221 B.C. (pp. 352-450). Cambridge: Cambridge University Press.

Seligson, S. (2003). El Mito de Dangun. Fundación del primer Estado coreano y origen de su identidad. Memoria electrónica del XI Congreso Internacional de ALADAA, 2003. México D.F. Recuperado de:

http://ceaa.colmex.mx/aladaa/imagesmemoria/silviaseligsonmito.pdf (25/05/2017)

Seth, M.J. (2010). A history of Korea. From antiquity to the present. Lanham: Rowman \& Littlefield Publishers.

Shaughnessy, E. (1999) Western Zhou History. En M. Loewe y E. Shaughnessy (Eds.). The Cambridge History of Ancient China. From the Origins of Civilization to 221 B.C. (pp. 292-352). Cambridge: Cambridge University Press.

Sturgeon, D. (Ed.) (2017a) 武英殿二十四史本《史記》. Chinese Text Project. Recuperado de: http://ctext.org/library.pl?if=en\&res=77688. (25/05/2017)

Sturgeon, D. (Ed.) (2017b), Shiji, “Song Weizi Shijia”. Chinese Text Project. Recuperado de: http://ctext.org/shiji/song-wei-zi-shi-jia (25/05/2017).

Sturgeon, D. (Ed.) (2017c). 武英殿十三經注疏 本 尚書正義. Chinese Text Project. Recuperado de: http://ctext.org/library.pl?if=en\&res=77713. (25/05/2017).

Swingle, W. (1921). Chinese Historical Sources. The American Historical Review, 26 (4), 717-725.

Watson, B. (Ed.) (1993). Records of the Grand Historian. Vol I-II. Nueva York: Columbia University Press.

Weber, M. (2002). Economía y Sociedad. Madrid: Fondo de Cultura Económica.

$\mathrm{Xu}$, S. (2012). Reconstructing ancient history: historiographical review of the ancient 
history of korea, 1950-2000. Asia Network Exchange, 19 (2), 14-22.

$\mathrm{Xu}$, S. (2016). Reconstructing Ancient Korean History. Lanham: Lexington Books.

Yao, X. (Ed.) (2003). The Encyclopedia of Confucianism, vol. I-II. Nueva York: Routledge.

Yu, Y. (1986). Han Foreign Relations. En D. Twitchett y M. Loewe (Eds.). The Cambridge History of China. The Ch'in and Han Empires, 221 B.C.-220 A.D. (pp. 377-463), vol. I. Cambridge: Cambridge University Press.

Para citar este artículo:

Santillán, Gustavo E. y Resiale Viano, José María (2018). El Reino Wiman Joseon: aproximaciones y perspectivas en torno a sus antecedentes y caracteres. Anuario de la Escuela de Historia Virtual, 13, 1-23. 